\title{
Expressões idiomáticas do espanhol em materiais didáticos do ensino fundamental para brasileiros
}

\author{
Camila Maria Corrêa Rocha (ROCHA, Camila Maria Corrêa) \\ Universidade Estadual de Londrina- UEL \\ cacamilaca@yahoo.com.br
}

Adja Balbino de Amorim Barbieri Durão (DURÃO, Adja Balbino de Amorim Barbieri) Universidade Estadual de Londrina- UEL

adja@uel.br

\begin{abstract}
Resumo
É imprescindível que o aprendiz de espanhol conheça e saiba usar as expressões idiomáticas, pois, além de serem registros culturais muito particulares, contribuem para que o estudante tenha uma formação que supere aspectos meramente lingüísticos. Temse, portanto, como objetivo abordar o ensino das expressões idiomáticas para estudantes brasileiros, o que será feito por meio da análise do modo como alguns livros didáticos de espanhol as apresentam e aplicam. Foram analisadas quatro coleções de livros direcionadas a estudantes brasileiros do ensino fundamental. Constatou-se que sua abordagem, na maior parte dos materiais, não levou em consideração suas particularidades como estruturas fixas de significado global.
\end{abstract}

Palavras-chave: expressão idiomática, livro didático, cultura.

\begin{abstract}
It is essential for Spanish language students to know and make good use of idiomatic expressions - as they contain specific cultural traits - and their inclusion in the language learning experience helps the students transcend solely linguistic aspects. The purpose of this research study was to examine how Spanish idiomatic expressions are being taught to Brazilian students, by analyzing how Spanish textbooks present and apply those expressions. Four sets of Spanish textbooks for elementary students were evaluated. It was found that most of the teaching material did not take into account their peculiarities as fixed structures of global meanings.
\end{abstract}

Keywords: idiomatic expression, textbook, culture. 


\section{Introdução}

Conhecer uma palavra é verdadeiramente complexo. Alonso (1999, p. 58) diz que só se conhece realmente uma palavra quando se é capaz de pronunciá-la e escrevêla corretamente, quando se consegue reconhecê-la tanto quando a mesma é pronunciada isoladamente como quando é combinada com outras, quando são conhecidas suas particularidades gramaticais e todos os significados que assume em cada situação comunicativa e, ainda, quando se sabe utilizá-la corretamente em cada contexto determinado. Considerando todos esses aspectos, entende-se que o processo de ensinoaprendizagem do léxico é muito mais complexo do que possa parecer.

Seguindo o explicitado por Costa (apud XATARA, 2001, p. 49), o ensino do léxico permaneceu à margem do ensino das línguas estrangeiras nas décadas de 50 e 60, devido à visão mecanicista-comportamental que regia as décadas posteriores, 70 e 80, por causa da visão mentalista-cognitiva. Nos anos 90, apesar de maior atenção ter sido dedicada ao léxico, posto que se ressaltava os repertórios de conteúdos lexicais a serem ensinados em cada fase de aquisição de uma língua estrangeira, LE, não se conseguiu solucionar todos os problemas que envolvem esse processo, tanto que, muitas vezes, o léxico é ensinado visando a objetivos tais como capacitar o aluno para interpretar textos, para compreender gravações em áudio, para praticar determinadas estruturas gramaticais, para aperfeiçoar a pronúncia ou para trabalhar a fluência oral e escrita, entre outros propósitos. Para Xatara (2001, p. 50), uma maneira de se otimizar os resultados do processo de ensino e aprendizagem do léxico seria recortar instâncias diferenciadas. Um desses recortes poderia ser o das expressões idiomáticas, as quais serão representadas pela abreviatura EI a partir de agora.

Labov (apud XATARA, 2001, p. 50) anuncia como marco zero para o estudo da língua a fala cotidiana dos falantes reais, cabendo, ao ensino, a tarefa de facilitar aos alunos a aquisição da competência lexical e de habilitá-los a usar palavras ou expressões que revelem sentimentos e sutilezas de pensamento do falante nativo da língua-alvo, as EI. Entretanto, Penadés Martínez (1999, p. 23) destaca que no ensino de segundas línguas, são freqüentes as dificuldades que supõem o ensino e, também, a aprendizagem de tais estruturas. O fato de as EI serem uma combinação fixa de palavras e de terem, geralmente, um significado diferente do que seus elementos têm se analisados isoladamente, justifica o esforço que um aprendiz de LE tem que fazer para incorporálas. Para o professor, também não é fácil ensiná-las, pois há uma carência de pesquisas que direcionem suas decisões sobre quais unidades ensinar em cada nível. Para responder às inquietações do professor, seria necessário que se desenvolvessem pesquisas que mostrassem o registro ao qual cada EI pertence, sua freqüência e suas condições de uso, mas, na maior parte das vezes, as publicações sobre as EI acabam por restringir-se a sua utilização em dicionários e em repertórios fraseológicos.

Durão e Rocha (2005, p. 132) postulam, em seu trabalho, que os alunos de LE deveriam ser expostos às EI desde os primeiros contatos com a LE (no caso específico de seu trabalho, alunos de espanhol). Corroborando esta idéia, Serey Leiva (1999, p. 107) considera essas expressões como um dos aspectos da língua que mais refletem a cultura, por isso elas não deveriam ser marginalizadas no processo de ensino e aprendizagem de línguas estrangeiras. Ou seja, conforme explica Xatara (2001, p. 58), é fundamental que haja, nas aulas de LE, um espaço reservado para o ensino das EI. Xatara (2001, p. 58) justifica a necessidade de o aluno ser exposto a tais expressões dizendo que: 
[...] elas são parte da sabedoria popular, expressam sentimentos, emoções, sutilezas de pensamentos dos falantes nativos, e serão de grande uso para os aprendizes. Traduzir e compreender uma EI, encontrar o seu equivalente em uma língua ou até mesmo explicá-la, ajudam os usuários a ultrapassarem os conhecimentos simplesmente veiculados nos textos e levam-nos a penetrar nas verdadeiras raízes da cultura popular.

Durão (1999, p. 140) sugere o estudo das EI como uma maneira de fazer com que o aluno constate os aspectos culturais da língua que está aprendendo, pois elas podem auxiliá-lo na compreensão de certas atitudes dos falantes da língua em questão.

De um modo geral, as EI são muito freqüentes na linguagem coloquial, pois, ainda que elas tenham um caráter previsível e seu uso seja automático por parte dos falantes nativos de uma língua, elas surpreendem por suas relações metafóricas e metonímicas, que as distanciam de seu sentido literal; neste sentido, a cada idiomatismo é atribuído um sentido conotativo no qual cada componente perde sua função nominativa e adquire, em conjunto com outros componentes, uma nova função (XATARA, 1998, p. 148).

Para os aprendizes de LE, há dificuldades na aquisição das EI, pois, segundo Xatara (2001, p. 50), além de conhecerem a gramática e o léxico da língua-meta, eles têm, ainda, que memorizar um grande repertório dessas estruturas cristalizadas, cujo significado é conotativo e metafórico, e saber adequá-las aos diferentes contextos comunicativos. De acordo com Silva (2003, p. 491), alguns autores chegam a afirmar que é impossível que o aluno adquira as EI completamente devido ao componente cultural que lhes é inerente.

No que se refere às características que distinguem as EI de outras estruturas, ainda que muitos autores as tenham concebido de maneiras diferentes, os pontos dos quais geralmente se parte para defini-las são a combinação de unidades e sua fixação formal e semântica, também chamada idiomaticidade.

Com respeito à fixação formal, considerada a característica mais peculiar das EI, Casares (apud PENADÉS MARTÍNEZ, 1999, p. 15) indica a impossibilidade de alterar seus componentes, assim como a relação sintática existente entre eles. Zuluaga (apud PENADÉS MARTÍNEZ, 1999, p. 15), por sua vez, defende que há graus de fixação formal, ou seja, algumas EI admitem que sejam intercaladas palavras à sua estrutura, alterações na ordem de seus componentes, modificações lexicais de alguns deles, bem como a substituição de um elemento por outro. Já Xatara (1998, p. 149) considera que cada EI é como "uma lexia complexa indecomponível, conotativa e cristalizada em um idioma pela tradição cultural”.

Quanto à fixação no plano do conteúdo, também chamada de idiomaticidade, Zuluaga (apud PENADÉS MARTÍNEZ, 1999, p. 17) define essa característica como uma particularidade semântica de certas estruturas cujo sentido não pode ser estabelecido a partir do significado de seus elementos nem da sua combinação. Desse modo, os componentes das EI perdem sua identidade e sua autonomia semântica, ainda que fora delas sejam verdadeiros signos lingüísticos. Nas palavras de Xatara (1998, p. 150):

[...] ela é um sintagma não composicional, oriundo de uma combinação de palavras que não formam uma unidade lexical e, por mutação semântica, passam a constituir uma unidade, porque os componentes do sintagma não podem mais ser dissociados significando uma outra coisa, ou seja, sua 
interpretação semântica não pode ser calculada a partir da soma dos significados individuais de seus elementos [...]

Tagnin (1988, p. 43) as classifica como expressões convencionais e idiomáticas, sendo que, às primeiras, pertenceriam os idiomatismos que podem ser compreendidos mediante a decomposição de seus termos, e, às segundas, as expressões idiomáticas, isto é, aquelas que não podem ser decodificadas literalmente, pois seu significado não resulta da somatória do significado dos elementos que as constituem.

Durão (2004, p. 155) classifica as EI como "expressões idiomáticas transparentes" e "expressões idiomáticas opacas”, que correspondem, respectivamente, às convencionais e às idiomáticas. Serey Leiva (1999, p. 108) considera como idiomáticas somente as expressões opacas e convencionais quanto ao significado; as outras são denominadas por ela expressões metafóricas.

Partindo das classificações e particularidades das EI expostas anteriormente, serão discutidas questões relativas a algumas EI do espanhol para estudantes brasileiros a partir da revisão de livros didáticos. Verificar-se-á se eles as apresentam e como o fazem, sob uma perspectiva qualitativa. Acredita-se que, por serem as EI uma combinação fixa de palavras cujo significado é global e metafórico, é necessário que os estudantes de espanhol sejam expostos a elas desde os primeiros estágios de aprendizagem da língua, por meio do material didático, entre outras maneiras.

Sevilla Muñoz e González Rodríguez (apud PENADÉS MARTÍNEZ, 1999, p. 35), ao tratarem das EI, propõem exercícios nos quais o aluno as conheça, as compreenda, consiga reutilizá-las e, por fim, memorize-as. Sob outra perspectiva, Pérez e Trenado (apud PENADÉS MARTÍNEZ, 1999, p. 35) acreditam que as unidades devem ser apresentadas indicando sua idiomaticidade e fixação; Xatara (2001, p. 52) também assume que o professor deve mostrar para o aluno os principais aspectos das EI, apresentando-as como uma unidade lexical indecomponível (sujeita a poucas variações), cujos elementos sofrem uma mutação semântica e são convencionais-, para que ele seja capaz de reconhecer tais características em cada texto ao qual seja exposto; para a compreensão de seu significado, ele deve aprender a explorar as relações de sentido possíveis que o contexto oferece, fazer associações e, nas palavras de Xatara (2001, p. 52):

[...] acionar uma estratégia metacognitiva que corresponda a um processo de recuperação de traços semânticos da expressão, ou seja, de uma elaboração do significado idiomático fundamentado em uma análise lexical literal.

Por outro lado, Vigara Tauste (apud PENADÉS MARTÍNEZ, 1999, p. 35) aponta o perigo de saturar o aluno com informações como as defendidas por Pérez e Trenado, e propõe apresentá-las partindo de um exemplo-base, e, posteriormente, admite a possibilidade de oferecer ao aluno listas de unidades fraseológicas que estejam divididas e organizadas por áreas temáticas.

Sevilla Muñoz e González Rodríguez (apud PENADÉS MARTÍNEZ, 1999, p. 36) acreditam que, primeiramente, o professor deve explicar o sentido e a origem da unidade; depois, deve mostrá-la isolada e, posteriormente, inserida em algum contexto específico, para que possa passar para a etapa de exploração, na qual são oferecidos sinônimos, assim como indicados os antônimos e sua freqüência de uso. Feito isso, poderiam ser propostos exercícios para comprovar se o aluno é capaz de reutilizar e memorizar as EI. 
Já Xatara (2001, p. 53) classifica os idiomatismos do francês de acordo com seu grau de dificuldade de compreensão, e, em seguida, propõe estratégias didáticas que, segundo ela, facilitam a aprendizagem. Esta classificação será apresentada neste trabalho e aplicada ao espanhol.

\section{Aspectos concernentes aos graus de dificuldade de aprendizagem das EI}

Ao grau de dificuldade 1, segundo Xatara (2001, p. 53), correspondem as expressões com equivalência literal no português, portanto, essas EI são as que oferecem pouca dificuldade de compreensão e são, por isso, recomendáveis para alunos de nível inicial; alguns exemplos desse tipo de EI poderiam ser: "tener los días contados” (ter os dias contados), “decir amén a todo” (dizer amém para tudo), entre outros. As EI com grau de dificuldade 2, de acordo com a referida autora, são aquelas cuja equivalência idiomática é semelhante no português; fazem parte deste grupo, por exemplo, EI como "pies para que os quiero" (pernas para quê te quero) e "borrar del mapa” (sumir do mapa) que, segundo o ponto de vista de Xatara, poderiam ser ensinadas a partir do $2^{\circ}$ semestre do primeiro ano até o $2^{\circ}$ ano. Para alunos de nível intermediário, com grau de dificuldade 3, conforme o ponto de vista de Xatara (2001, p. 54), seria aconselhável trabalhar com EI cuja tradução encontrasse uma correspondência em português, ainda que nesta língua fosse formada por vocábulos diferentes; enquadram-se nesse grupo, entre outras, as EI "por el canto de un duro" (por um triz), "tirar las patas por alto" (soltar os cachorros). Ao último grupo pertencem aquelas unidades fraseológicas que a autora classifica como tendo grau de dificuldade 4, motivo pelo qual elas são recomendadas para estudantes de nível avançado, já que elas revelam visões de mundo diferentes, ou seja, são aquelas EI que não possuem correspondência idiomática literal no português; a EI “¡habló el buey y dijo mu!” exemplifica este grupo.

Além de classificá-las por nível, Xatara (2001, p. 55) propõe, também, estratégias que o professor poderia usar no sentido de amenizar as dificuldades que a aprendizagem das EI supõe. Segundo a citada professora, o professor deveria associálas aos seus correspondentes no português, fazendo com que os alunos compreendessem seu significado por meio de desenhos ou figuras que representassem as idéias expressas pelas EI, além de partir de explicações em LE para chegar ao seu sentido, e, ainda, propor EI sinônimas, inserindo-as em textos curtos para que sejam compreendidas em contextos concretos.

Segundo Durão (2004, p. 101), os pontos de interseção entre o português e o espanhol, por um lado favorecem o processo de ensino e aprendizagem do espanhol como LE e, por outro, são claros obstáculos para o pleno domínio do idioma. O fato de haver semelhanças entre essas duas línguas irmãs, curiosamente, em determinados momentos chega a dificultar o processo de aprendizagem, pois, segundo essa autora, os aprendizes não se esforçam o necessário para aprendê-las por considerarem a idéia préestabelecida de que o espanhol é “fácil”.

Gurillo (apud PENADÉS MARTINEZ, 1999, p. 19) acredita que as expressões idiomáticas só devem ser ensinadas a alunos que tenham alcançado um nível de conhecimento intermediário ou avançado do idioma, pois, aos iniciantes, falta o domínio de esquemas culturais, históricos e religiosos que permitiriam e facilitariam a apreensão dessas EI. Forment Fernández (1998, p. 1), assim como Gurillo, defende que não é conveniente que alunos de níveis inicial e intermediário da língua espanhola se 
defrontem com os idiomatismos, em virtude de eles apresentarem peculiaridades morfológicas e sintáticas que podem influenciar de maneira negativa a aprendizagem das questões lingüísticas básicas. Forment Fernández (1998, p. 1) realizou uma pesquisa, inicialmente, com base em materiais didáticos procedentes da Espanha, para os níveis inicial e intermediário, através da qual pôde constatar que, na maior parte das vezes, as EI aparecem em um ou outro texto, visando somente a um primeiro contato entre elas e o aluno, e são, simplesmente, esclarecidas quanto ao seu significado. Os materiais direcionados para o nível avançado, ao contrário, destinam um espaço especialmente para as EI em todas as unidades, posto que, nesta etapa de estudo, o estudante deve ser exposto a uma língua que seja parecida à de um falante nativo, conforme expõe essa autora. Os exercícios para verificar se houve aprendizagem consistem em espaços em branco em textos, nos quais o aluno, a partir de algumas frases que servem como contexto, deve preenchê-los com as EI que lhe pareçam adequadas; para cada espaço, há opções. Fazendo isso, segundo a referida autora, é possível avaliar se o aluno aprendeu a usá-las. Além desse tipo de exercício, é imprescindível que o professor esclareça para o aluno a freqüência de uso das EI, destacando, por exemplo, se é usada em textos orais e/ou escritos e as características sócio-lingüísticas dos falantes que as utilizam, já que tais expressões pertencem a uma comunidade na qual ele não está inserido.

Um recurso que sempre foi muito utilizado na didática do vocabulário são as listas, os inventários de vocábulos para serem memorizados. Segundo Forment Fernández (1998, p. 2), ainda que as teorias metodológicas mais atuais condenem a prática da memorização, se houvesse algumas modificações na elaboração dessas listas, elas poderiam vir a ser de grande utilidade para os aprendizes; a autora propõe, então, que os modismos sejam apresentados em função de situações comunicativas e que a cada EI sejam acrescentadas informações relativas às questões gramaticais e léxicas envolvidas nelas. A autora propõe, ainda, uma maneira de agrupar e trabalhar as EI; para exemplificar, ela usa somente as EI relacionadas aos vocábulos “ojos, cabeza, pie y boca”. Para cada vocábulo, seleciona os idiomatismos que contêm essas palavras baseando-se nas principais atividades que podem ser relacionadas a cada um (e.g.: com a palavra boca, ela agrupou: andar una cosa / alguien de boca en boca, callar la boca, cerrar la boca de alguien, que significam, respectivamente, estar na boca do povo, ficar quieto e fechar a boca de alguém).

Penadés Martínez (1999, p. 42) aponta aspectos que devem ser levados em conta pelo professor ao ensinar as EI visando facilitar sua aprendizagem: a memorização, a sinonímia, a hiponímia e a antonímia. No que se refere à memorização das unidades fraseológicas, desde o âmbito da Lingüística Teórica à Psicolingüística, ficou comprovado que os signos lingüísticos podem se associar um ao outro pelo fato de estarem ligados por graus de semelhança que estão entre a equivalência dos sinônimos e o núcleo comum dos antônimos. Neste sentido, estabeleceram-se regras de associação de palavras, que também podem ser estendidas às expressões fixas, dentre elas, a do contraste mínimo, segundo o qual, como postula Penadés Martínez (1999, p. 96), um estímulo (um idiomatismo dado) sempre sugerirá seu oposto (antônimo), ou seja, os antônimos serão a resposta mais freqüente ao estímulo dado. Para Forment Fernández (1998), a memorização ajuda no domínio das EI, porém, por não haver estudos que a aprofundem como um procedimento de ensino, ela deixou de ser usada como recurso na aquisição das LE.

Quanto à sinonímia das expressões idiomáticas, partindo do princípio de que a identidade ou quase identidade de significado de duas ou mais unidades fraseológicas 
determina se elas são sinônimas ou quase sinônimas; Penadés Martínez (1999, p. 43) diz ser possível estabelecer unidades que compartam essa relação de sinonímia; no entanto, alguns idiomatismos, apesar de terem o mesmo significado, não são considerados sinônimos e sim variantes de uma mesma EI, como ocorre, por exemplo, em "dormir como un leño/ dormir como un lirón”, onde há apenas uma modificação no léxico, mantendo-se a identidade do significado.

De acordo com Penadés Martínez (1999, p. 46), o termo hiponímia é utilizado para designar a relação de significado entre unidades léxicas subordinadas a outra mais genérica, sendo esta última o hiperônimo das unidades léxicas subordinadas (hipônimos). Com respeito às EI, a relação hiperonímia-hiponímia é importante para a práxis lexicográfica por serem freqüentes as definições baseadas nesta relação; são exemplos: "dormir a pierna suelta", "dormir como un bendito" e "dormir como un santo”, que remetem à idéia de dormir demais; nelas, o verbo dormir é o hiperônimo das locuções verbais, que são os hipônimos, além de ser o componente principal das unidades e o que permite classificá-las como locuções verbais (PENADÉS MARTÍNEZ, 1999, p. 47).

Por fim, podem aparecer idiomatismos nos quais a antonímia aparece explícita em seus elementos, como por exemplo, "coger a la izquierda" e "coger a la derecha", como também duas unidades podem constituir uma relação de antonímia sem que haja lexemas que marquem tal relação, como é o caso de "tener leche" e "tener la negra", que significam, respectivamente, 'estar com sorte’ e 'estar com azar’.

\section{Considerações metodológicas e análise das EI presentes nos livros didáticos selecionados}

Para a realização desta pesquisa, foram selecionadas quatro coleções de livros didáticos do aluno para ensino da língua espanhola no nível Fundamental, todas direcionadas a estudantes brasileiros, as quais serão chamadas, neste trabalho, de coleção A (4 volumes), coleção B (4 volumes), coleção C (4 volumes) e coleção D (4 volumes). A análise desses materiais tomou por base dois critérios: verificar se esses livros, ao apresentarem as expressões idiomáticas, partiram da consideração das questões teóricas antes explicitadas (definição e características) e verificar se a presença ou ausência das EI é condizente com a proposta metodológica explicitada nas páginas iniciais do livro do aluno.

Para a realização da análise foram considerados conceitos de EI que se complementam. Dentre eles, o do lingüista soviético Kunin (apud PENADÉS MARTÍNEZ, 1999, p. 12), que as define como "um grupo de palavras ou uma oração com um coeficiente mínimo de estabilidade no nível fraseológico”, o de Zuluaga, que as vê como "uma combinação fixa de palavras” (apud PENADÉS MARTÍNEZ, 1999, p. 13), o do lingüista checo Cermak (apud PENADÉS MARTÍNEZ, 1999, p. 13), que defende que uma EI é um "sintagma fixo e estável de elementos no qual pelo menos um deles é membro de um paradigma rigorosamente restrito e fechado quanto à forma e, algumas vezes, semanticamente” e o de Xatara (1998, p. 8), para quem a expressão idiomática "é uma lexia complexa indecomponível, conotativa e cristalizada em um idioma pela tradição cultural”. Além dessas definições, será considerada a classificação de Tagnin (1988, p. 43), que identifica as EI como expressões convencionais e idiomáticas, sendo que às primeiras pertenceriam os idiomatismos, os quais podem ser compreendidos mediante a decomposição de seus termos e às segundas, as EI, que não 
podem ser decodificadas literalmente, pois seu significado não é a somatória do significado dos elementos que as constituem. E, ainda, conforme dissemos antes, a de Durão (2004, p. 155) que as classifica como "expressões idiomáticas transparentes” e “expressões idiomáticas opacas”, que correspondem, respectivamente, às convencionais e às idiomáticas.

A primeira coleção, a qual denominou-se A, é composta de quatro volumes; o volume 1 possui seis unidades, sendo que a cada três, há uma de revisão. Quanto à presença de EI, somente na unidade 4, cujo tema é o corpo humano, são apresentadas algumas expressões com o título "Expresiones populares", que estão agrupadas a partir dos substantivos relacionados ao corpo humano ("asomar la cabeza", "quemarse las cejas", "morderse los codos de hambre”, “dormir a pierna suelta”, "tener la mano larga", "andar con ojos", "quedarse con un palmo de narices", "no tener pelos en la lengua" e "no dar pie con bola").

Acreditamos que, de certa forma, foram estabelecidos critérios que justificam a escolha dos tópicos sob os quais elas foram organizadas, tendo em vista que o tema da unidade era o corpo humano. No entanto, não há explicações sobre seu significado, sobre a freqüência de uso e origem, como julga importante Sevilla Muñoz e González Rodríguez (apud PENADÉS MARTÍNEZ, 1999, p. 35), com quem concordamos. Também não se percebe a preocupação por apresentar somente expressões idiomáticas cujo sentido possa ser compreendido mediante sua tradução literal, já que o livro é para iniciantes, como Xatara (2001, p. 53) propõe. Ao contrário, a maioria das EI apresentadas são opacas, ou seja, possuem sentido metafórico, o qual não é devidamente explorado no contexto da unidade.

Com respeito aos exercícios, são propostos dois: no primeiro são dadas explicações e pede-se que o aluno, intuitivamente, tente associá-las aos idiomatismos e no segundo, pede-se que eles completem as frases com a EI mais adequada ao contexto. De modo geral, os exercícios estão de acordo com o que os estudiosos propõem, ou seja, eles levam o aluno a conhecer e compreender as EI, porém, faltam procedimentos que permitam ao aluno ser capaz de reutilizá-las, além de não serem exploradas as relações de sinonímia, de antonímia e de hiponímia, que poderiam facilitar sua aprendizagem.

O volume 2 não apresenta nenhuma expressão idiomática; o volume 3, apresenta um diálogo que contém algumas EI, sob o título "Expresiones populares”, e, em seguida, é pedido que o aluno as relacione com seu significado, devendo compreendê-las pelo contexto. Essas expressões são: "estar a gusto", "ser muy gracioso”, "hacer puente”, “decir piropos” e "no caer”, que significam, respectivamente, estar à vontade, alguém não ter nenhuma graça, emendar um feriado, paquerar, não se lembrar de algo; à exceção de "estar a gusto", que pertence ao grau de dificuldade 1 , estas EI pertencem, segundo Xatara (2001), ao grau de dificuldade 3, ou seja, sua tradução encontra uma correspondência no português, mas é formada por vocábulos distintos, e são recomendáveis, portanto, para o volume 3 do livro onde são encontradas. No volume 4 é apresentada uma lista com 29 expressões idiomáticas opacas intituladas como "Modismos". Essas EI aparecem em ordem alfabética, seguidas da tradução de cada uma ao português. Essa apresentação é justificada por elas constituírem uma das dificuldades que enfrenta o estudante ao aprender espanhol. Em seguida, o livro traz um exercício no qual o aluno deve escolher cinco EI entre as apresentadas para elaborar uma frase com cada uma. Percebe-se que não houve critérios para a seleção das EI; acreditamos que elas devem ser apresentadas em função de situações comunicativas e que a cada uma devem ser acrescentadas informações relativas a questões gramaticais e 
léxicas. Concordamos com Silva (2003, p. 497) que defende que devem ser especificados sua definição, um exemplo de seu uso, seu equivalente no português e um exemplo de uso do equivalente. Pode-se inferir, desta primeira análise, que as EI realmente são apresentadas de forma assistemática, pois elas apareceram somente em três dos quatro volumes da coleção e uma só vez em cada livro. Outra questão é que o material não vem acompanhado de um manual que instrua o professor sobre como proceder ao abordá-las, além de não ser explicitada a base teórica na qual o material se baseia. Portanto, não é possível averiguar se a apresentação das EI está condizente com a metodologia utilizada.

A coleção B, por sua vez, também é composta de quatro volumes. Cada um possui seis módulos compostos de seis unidades. Nos volumes 1 e 2 não aparecem expressões idiomáticas. No volume 3 , na unidade 9, há um texto intitulado "manos a la obra”, no qual estão presentes duas EI que, assim como a que está presente no título, são consideradas por nós, transparentes, segundo a classificação de Durão (2004, p. 155) ("no oírse ni una mosca" e "ponerse rojo como un tomate”, cujo significado é respectivamente, não ouviu um pio e enrubescer), entretanto essas EI não são exploradas nem reconhecidas como tal; no final desta unidade, elas aparecem no resumo dos principais conteúdos da unidade intitulado "Vocabulario", e junto a elas são colocadas outras unidades lexicais que o autor parece ter considerado como EI, mas que não o são, de acordo com a nossa concepção ("érase una vez”, "colorín colorado, este cuento se ha acabado" e "fueron felices y comieron perdices"). Percebe-se que ao generalizar todas as estruturas como EI, o autor tem a mesma concepção de Penadés Martínez (1999, p. 12), para quem as EI são termos genéricos que estão cada vez mais se impondo para denominar um conjunto que engloba as expressões fixas, os modismos, os provérbios, as unidades pluriverbais, lexicalizadas e habitualizadas e as expressões idiomáticas.

Na unidade 19, há um texto cujo título é “Expresiones coloquiales”, no qual se explica que em português e em espanhol existem palavras e expressões que são próprias da língua falada; em seguida, são apresentadas algumas frases com o título "Más expresiones coloquiales”, onde elas são empregadas visando a esclarecer seu sentido. Pede-se que o aluno, depois de conhecê-las, resolva um exercício que consiste em relacionar cada expressão ao seu significado. No final da unidade, elas aparecem no resumo dos principais tópicos vistos e sua presença é justificada pelo fato de serem consideradas estratégias que auxiliam o aluno a se expressar de forma mais apropriada em uma conversa espontânea e familiar.

Comparando a maneira como elas foram propostas na unidade 9 e na 19, pôde-se constatar que, na segunda, houve uma preocupação em esclarecer para o aluno que aquelas estruturas eram EI, ao contrário do primeiro aparecimento delas (na unidade 9), onde seu significado não foi explorado. Acreditamos que a presença do texto na unidade 19 foi importante no sentido de que familiarizou os alunos com elas, porém, poderiam ter sido incluídas nele suas particularidades, ou seja, sua idiomaticidade, sua mutação semântica e convencionalidade, conforme propõe Xatara (2001, p. 184), já que nos exercícios havia EI transparentes e opacas que exemplificavam tais características. Também pudemos perceber que, na unidade 19, elas foram exploradas, em parte, como propõem Muñoz e Rodrígues (apud PENADÉS MARTÍNEZ, 1999, p. 35), para quem o aluno deve conhecê-las e compreendê-las, mas faltaram procedimentos que propusessem sua reutilização e, posteriormente, sua memorização; esta última etapa, julgamos ser uma tarefa mais complexa, já que, segundo Xatara (2001, p. 58), as EI são parte da sabedoria popular, expressam sentimentos, emoções, sutilezas de pensamentos 
dos falantes nativos e, por isso, demoram muito mais tempo para serem interiorizadas, se comparadas às outras estruturas da língua objeto de estudo.

Quanto ao volume 4, na unidade 4, há um teste psicológico intitulado "Dicho y hecho”. Dele são retiradas algumas EI referentes às partes do corpo; a elas são acrescentadas outras EI pertencentes ao mesmo campo semântico com suas respectivas explicações e contexto de uso e pede-se que o aluno complete as frases com a EI mais adequada ao contexto. Constatamos que há pontos positivos e negativos nesta unidade. O diferencial neste exercício é que as frases são ilustradas, o que facilita a identificação dos sentidos, pois os desenhos sugerem o seu significado. Para Xatara (2001, p. 55), usar figuras que sugiram o significado das EI, dar explicações sobre elas em LE e inserilas em textos curtos, como se vê nesta unidade, são recursos que podem amenizar as dificuldades que sua aprendizagem supõe. Por outro lado, acreditamos que tais EI deveriam ter sido propostas na unidade cujo tema fosse o corpo humano, como se fez no volume 1 da coleção $A$, pois, neste contexto, elas fariam muito mais sentido para o aluno por estarem contextualizadas.

De acordo com o manual do professor, são as necessidades comunicativas que ditam a ordem dos conteúdos formais a serem estudados, o que nos leva a inferir que o enfoque metodológico no qual o livro se baseia é o comunicativo. Segundo Santos Gargallo (1999, p. 69), são características desse método a língua concebida como um instrumento de transmissão de significado, a ênfase na compreensão e produção oral, o conceito de competência comunicativa, que supõe o domínio de conhecimentos sócioculturais, discursivos, estratégicos e lingüísticos. Nesta perspectiva, conclui-se que, por considerarmos as EI conhecimentos sócio-culturais que colaboram para o aluno atingir a competência comunicativa, conforme o plano curricular do Instituto Cervantes (apud PENADÉS MARTÍNEZ, 1999, p. 24), elas deveriam constar nos quatro volumes do material de forma sistemática e planejada e não da maneira como foi constatado.

Outra coleção, a que foi denominada C, também é composta por 4 volumes. Segundo o que propõe o material, a língua é entendida como um instrumento de comunicação que permite às pessoas articular pensamentos e expressar-se com clareza; para os autores do material, aprender um idioma não significa somente conhecer regras gramaticais. Por isso, são desenvolvidas questões formais da língua, as competências estratégica, discursiva e sócio-cultural e a idéia do aluno autônomo no processo de ensino e aprendizagem, preceitos todos pertencentes ao método comunicativo.

A análise dos livros mostra que, no que concerne às EI, há incoerências entre o que se propõe e o que se vê, pois os volumes 1 , 2 e 4 do material não as apresentam. $O$ volume 3, na unidade 8, traz algumas EI sob o título "En la punta de la lengua”, porém, elas não são reconhecidas como tal, ao contrário, elas aparecem em função de outro objetivo que não seu estudo propriamente dito, ainda que no manual do professor esse tópico seja apresentado como sendo uma atividade que promova a aquisição de um vocabulário útil para o aluno. Vale ressaltar, também, que é dito no manual que as autoras do material o elaboraram focalizando os conteúdos de espanhol que mais oferecem dificuldades aos alunos brasileiros. Xatara (2001, p. 50), assim como nós, acredita que há dificuldades na aquisição das EI, pois, além de conhecer a gramática e o léxico da língua meta, o aluno tem, ainda, que memorizar um grande repertório de estruturas cristalizadas, cujo significado é conotativo e metafórico e saber adequá-las aos diferentes contextos comunicativos.

A última coleção destinada ao Ensino Fundamental, a D, é também composta de 4 volumes. Somente no último aparecem EI, ainda que na apresentação do livro seja dito que fazendo uso do material o aluno alcançará um grau de competência lingüística 
que permita sua atuação em qualquer situação comunicativa. $O$ último volume do material, o 8, propõe algumas EI ("hacerse daño", para referir-se a fazer ou causar o mal, "subir en hombros", ou seja, explorar, "coger en brazos", cujo significado é tomar nos braços, pegar no colo e "echarse a llorar”, cair em pranto) em um exercício no qual se pede que o aluno tente associá-las ao seu significado em uma história em quadrinhos. A nosso ver, esse tipo de atividade é útil, já que oferece ilustrações para facilitar a apreensão das EI e as insere em um contexto, mas faltaram esclarecimentos sobre o significado das EI e outros exercícios nos quais o aluno as reutilizasse visando a memorizá-las, como propõe Xatara (2001, p. 53).

Quanto à base teórica, conforme explicitado no material, ela assenta no método comunicativo porque, segundo o guia didático, o curso é centrado no aluno, a função básica da linguagem é a comunicação e as atividades objetivam reforçar a função comunicativa da língua; no entanto, na prática, pôde-se observar que o tratamento dado às EI não esteve de acordo com o método comunicativo.

\section{Considerações finais}

De um modo geral, as quatro coleções apresentaram EI, porém, os livros pertencentes às coleções $\mathrm{A}$ e $\mathrm{B}$ as apresentaram três vezes ao longo dos quatro volumes do material, enquanto as coleções C e D apenas uma vez. A ausência de tais estruturas foi maior nos livros para níveis iniciais de estudo da língua. Para Gurillo (apud DURÃO, 2005, p. 131), as dificuldades que implicam o ensino das EI nestes níveis, tais como a falta de domínio de esquemas culturais e a necessidade de que sejam apresentadas em contextos situacionais-comunicativos específicos, entre outros aspectos, exigem um conhecimento consistente do idioma, o que falta aos iniciantes.

Com este trabalho pretendeu-se refletir sobre a necessidade de se conceder às expressões idiomáticas um papel importante nos estudos orientados ao ensino de espanhol como língua estrangeira. Tomamos como características que as distinguem de outras unidades lexicais: sua indecomponibilidade (quase não existe possibilidade de substituição dos elementos que as constituem), seu sentido conotativo (sua interpretação semântica não pode ser feita com base nos significados individuais de seus elementos) e sua cristalização (consagração de um significado estável).

O professor deve saber como apresentar as EI, levando em consideração suas particularidades. Penadés Martínez (1999, p. 23) sustenta que, na fase de apresentação, o professor deverá proporcionar ao aluno, na medida do possível, indicações sobre o registro de cada EI, sobre seu contexto de uso através de exemplos e sobre sua origem. Forment Fernández (1998, p. 2) também chama a atenção para o tratamento que deve ser dado aos idiomatismos opacos, pois, segundo a autora, estudá-los implica falar de ritos, crenças religiosas e superstições, ou seja, de questões culturais subjacentes à sua compreensão.

Conforme explicitado anteriormente, Labov (apud Xatara, 2001, p. 50), em 1975, já anunciava como marco zero para o estudo da língua a fala cotidiana dos falantes reais, cabendo, ao ensino, a tarefa de facilitar aos alunos a aquisição da competência lexical e de habilitá-los a usar também as palavras ou expressões que revelam os sentimentos e as sutilezas de pensamento dos falantes das línguas, as expressões idiomáticas. Para Serey Leiva (1999, p. 107), as EI são um dos aspectos da língua que mais refletem a cultura, por isso não devem ser marginalizadas do processo 
de ensino e aprendizagem de línguas, tendo em vista que são registros coloquiais do qual fazem uso os falantes nativos em vários contextos, inclusive no contexto escolar.

Uma vez que as EI são usadas em contextos diversos, é, portanto, essencial que o aluno de espanhol seja exposto a elas no contexto escolar desde os níveis iniciais de estudo do espanhol. Ainda assim, ficarão algumas perguntas elaboradas por Xatara (1995, p. 195), mas que são pertinentes a este trabalho e que cabem ao professor, às instâncias escolares, de um modo geral, e às editoras refletirem e tentarem responder: por que há ainda um número reduzido de estudos aprofundados sobre as expressões idiomáticas? Por que muitas EI não fazem parte dos dicionários? Por que há tão pouco espaço para as EI nas gramáticas? Por que, enfim, as EI são tratadas como um problema marginal na pesquisa lingüística e no ensino e aprendizagem de línguas estrangeiras?

\section{Referências}

ALONSO, Encina. Enseñar vacabulario. In: ¿Cómo ser profesor/a y querer seguir siéndolo? Madrid: Edelsa, 1999. p. 57-68.

BRASIL, Secretaria de Educação Fundamental. Parâmetros Curriculares Nacionais: terceiro e quarto ciclos do ensino fundamental: língua estrangeira. Brasília: MEC/SEF, 1998.

DURÃO, Adja B. de A. B. Análisis de errores en la interlengua de brasileños aprendices de español y de españoles aprendices de portugués. 2. ed. Londrina: Eduel, 2004.

- A importância da explicitação de matizes culturais particulares no ensino de línguas estrangeiras. Signum: estudos da linguagem, Londrina, n. 2, p. 139-154, 1999.

; ROCHA, Camila M. C. Expressões idiomáticas do espanhol: um osso duro de roer! In: DURÃO, Adja B. de A. B. et al. (Orgs.). Vários olhares sobre o espanhol: considerações sobre a língua e a literatura. Londrina: Universidade Estadual de Londrina, 2005. p. 131-166.

FORMENT FERNÁNDEZ, María del Mar. La didáctica de la fraseología ayer y hoy: del aprendizaje memorístico al agrupamiento en los repertorios de funciones comunicativas. Especulo, n. 10. Madrid: Universidad Complutense de Madrid, 1998. Disponível em: http:// www.ucm.es/info/especulo/numero10/did_fras.html . Acesso em: 04 out. 2005.

PARANÁ, Secretaria da Educação. Diretrizes curriculares para o ensino fundamental: língua estrangeira moderna. Disponível em:

http://www.diadiaeducacao.com.br/diretrizes . Acesso em: 20 set. 2005.

PENADÉS MARTÍNEZ, Inmaculada. La enseñanza de las unidades fraseológicas. Madrid: Arco Libros, 1999.

SANTOS GARGALLO, Isabel. Lingüística Aplicada a la enseñanza- aprendizaje del español como lengua extranjera. Madrid: Arco Libros, 1999. p. 45- 84. 
SEREY LEIVA, Myriam J. Expresiones idiomáticas: una marca cultural. In: La enseñanza del español a lusohablantes: dificultades y estrategias- VII Seminario, 1999.

SILVA, Maria Eugênia O. de O. Los medios de comunicación como tema condecente al aprendizaje de la fraseología. In: XIV Congreso Internacional de ASELE. Burgos:

Universidade Federal da Bahia, 2003, p. 486-498.

TAGNIN, Stella E. O. A tradução dos idiomatismos culturais. Trabalhos em Lingüística Aplicada, Campinas, n. 11, p. 43-52, 1988.

XATARA, Cláudia M. O campo minado das expressões idiomáticas. Alfa: Revista de Lingüística, São Paulo, v. 42, n. esp., p. 147-159, 1998.

O ensino do léxico: as expressões idiomáticas. Trabalhos em Lingüística

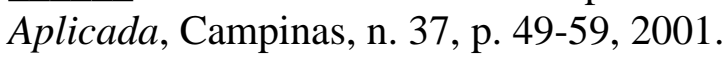

. O resgate das expressões idiomáticas. Alfa: Revista de Lingüística , São Paulo: UNESP, v. 39, p. 195-210, 1995.

\section{Materiais didáticos}

ARTUÑEDO, Belén; DONSON, Cynthia. ¡Adelante!: Comunicación en español 7. São Paulo: FTD, 2002.

ARTUÑEDO, Belén; DONSON, Cynthia. ¡Adelante!: Comunicación en español 8. São Paulo: FTD, 2002.

BOROBIO, Virgilio. ¡Adelante!: Comunicación en español 5. São Paulo: FTD, 2002. . ¡Adelante!: Comunicación en español 6. São Paulo: FTD, 2002.

CALLEGARI, Marília Vasques; RINALDI, Simone. ¡Arriba! v. 1. São Paulo: Moderna, 2004.

CALLEGARI, Marília Vasques; RINALDI, Simone. ¡Arriba! v. 2. São Paulo: Moderna, 2004.

GARCÍA, María De Los Ángeles; HERNÁNDEZ, Josephine Sánchez. Español sin fronteras: curso de lengua extranjera. v. 1. São Paulo: Scipione, 2002.

GARCÍA, María De Los Ángeles; HERNÁNDEZ, Josephine Sánchez. Español sin fronteras: curso de lengua extranjera. v. 2. São Paulo: Scipione, 2002.

GARCÍA, María De Los Ángeles; HERNÁNDEZ, Josephine Sánchez. Español sin fronteras: curso de lengua extranjera. v. 3. São Paulo: Scipione, 2002. 
GARCÍA, María De Los Ángeles; HERNÁNDEZ, Josephine Sánchez. Español sin fronteras: curso de lengua extranjera. v. 4. São Paulo: Scipione, 2002.

GONZÁLEZ, Jesús Fernández; MOZOS, Emilio Prieto De Los. Español Para Todos. v. 1. São Paulo: Ática \& Universidad de Salamanca, 2003.

GONZÁLEZ, Jesús Fernández; MOZOS, Emilio Prieto De Los. Español Para Todos. v. 2. São Paulo: Ática \& Universidad de Salamanca, 2003.

GONZÁLEZ, Jesús Fernández; MOZOS, Emilio Prieto De Los. Español Para Todos. v. 3. São Paulo: Ática \& Universidad de Salamanca, 2003.

GONZÁLEZ, Jesús Fernández; MOZOS, Emilio Prieto De Los. Español Para Todos. v. 4. São Paulo: Ática \& Universidad de Salamanca, 2003.

NOVICK, Beatriz; OSUNA, Miriam. ¡Arriba! v. 4. São Paulo: Moderna, 2004.

SUÁREZ, Freddy Rodríguez; RODRÍGUEZ, Ginger de la Torre. ¡Arriba! v. 3. São Paulo: Moderna, 2004. 